\title{
El huésped de Amparo Dávila, del ansia al horror
}

Amparo Dávila's El huésped, from anxiety to horror

\author{
Iram Isaí Evangelista Ávila \\ https://orcid.org/0000-0002-1065-082X \\ Jesús Erbey Mendoza Negrete \\ https://orcid.org/0000-0003-2122-4516 \\ Adriana Ramírez Caballero \\ https://orcid.org/0000-0002-9230-0363 \\ Universidad Autónoma de Chihuahua, Chihuahua, México \\ Contacto: ievangelista@uach.mx
}

\begin{abstract}
Resumen
El presente artículo aborda el tema del horror en el cuento El huésped de Amparo Dávila desde varios puntos de vista. Por una parte, propone demostrar que la protagonista atraviesa por las fases de ansiedad y angustia dentro de la trama, las cuales la llevan al horror. Asimismo, se plantea la representación del antagonista como un ente que guarda un doble significado en el desarrollo de la narración. Se expone, además, que la trama del cuento fantástico necesita un tipo de lector participativo, el cual termine la construcción de la narrativa. Estos rasgos distintivos se pondrán en relieve a través del relato en cuestión.
\end{abstract}

Palabras clave: Amparo Dávila; Agitación; Síntomas; Símbolo; Refiguración.

\begin{abstract}
This article discusses the idea of horror in Amparo Dávila's short Story El huésped from different points of view. First, it attempts to demostrate how the protagonist from Amparo Dávila's short-story goes through the stages of anguish and anxiety within the plot of the story, all of which will lead her to horror. Likewise, the representation of the antagonist is suggested as an entity that carries a double meaning in the development of the narrative. It also discusses how the plot in a fantasy short story requires an active reader who will collaborate with the completion of the narrative. These distinctive features will be highlighted through the story analyzed here.
\end{abstract}

Keywords: Amparo Dávila; Turmoil; Symptoms; Symbol; Reconfiguration.

Recibido: 02.12.17 Aceptado: 30.06 .18 


\section{Introducción}

El siguiente análisis del cuento de Amparo Dávila (2014) aborda algunas situaciones que acontecen en el texto y en la acción de los personajes. Así la ansiedad, la angustia y el horror, proponen expectativas de interacción con el lector del cuento de Dávila. Se aborda también al antagonista como un símbolo, el cual posee una influencia dañina hacia el personaje principal femenino. El objetivo principal es valorar el cuento daviliano como una estructura que posee varios puntos de vista, los cuales afloran cuando el lector se asume como uno partícipe y activo, desentrañando las diversas posibilidades del texto narrativo. Las fuentes principales son el estudio de Sierra, Ortega y Zubeidat (2003), así como las pautas que da Lovecraft $(2014 ; 2016)$ acerca del horror y Beuchot con sus reflexiones sobre el símbolo (2004; 2007).

\section{Ansiedad}

El estado de ansiedad en la protagonista de Dávila (2014) emerge debido a las situaciones conflictivas con las que interactúa el personaje. Lo anterior es el comienzo del viaje que la llevará hasta el funesto desenlace del cuento. ¿Qué sucede para que el personaje femenino engendre esta enfermedad? Son varias las situaciones con las que comulga para que vaya desenvolviéndose dicha disposición. Su aislamiento y el moverse en espacios reducidos son características que hace que experimente sentimientos y situaciones desagradables que mellan su estabilidad mental. También se somete a la opresión causada por el ambiente y su hábitat; de esta manera, la ansiedad cobra fuerza y comienza a flaquear su espíritu de lucha, pierde su estado de voluntad, evoluciona una sintomatología agudizada por el aislamiento que la oprime y que colapsa gracias al tétrico invitado traído por el marido. Lo anterior comienza a germinar un cuadro de ansiedad que va tornándose crónica, y que es el detonante de la trama de la narración. Con respecto al estado de ansiedad en el que se encuentra la protagonista, Sierra, Ortega y Zubeidat mencionan lo siguiente:

La ansiedad rasgo y estado se solapan en varios aspectos, al igual que le ocurre a la ansiedad crónica y la de tipo agudo; cuando ésta es intensa origina un sentimiento desagradable de terror e irritabilidad, acompañado de fuertes deseos de correr, ocultarse y gritar, presentando sensaciones de 
debilidad, desfallecimiento y desesperación para el individuo; también, puede haber un sentimiento de irrealidad o de "estar separado" del suceso o la situación (Sierra, Ortega y Zubeidat, 2003, p.16)

Estos rubros cobran narrativa dentro del cuento a analizar. La protagonista se encuentra inmersa en una atmósfera propicia a la pérdida de equilibrio. Así, la inestabilidad emocional, el estrés, junto con la ansiedad crónica, son conflictos que debe sortear diariamente, y que en conjunto crean el horror de la trama de Amparo Dávila.

Antes de proseguir, es necesario hacer mención que para Sierra et ál., los trastornos de ansiedad y angustia poseen mayores similitudes que distinciones y que es común familiarizar estos términos antes que diferenciarlos. El siguiente trabajo seguirá la recomendación de Sierra, pero también encontramos en su discurso el siguiente señalamiento con respecto a las terminologías. La ansiedad se menciona como un: "un estado de agitación e inquietud desagradable caracterizado por la anticipación del peligro, el predominio de síntomas psíquicos y la sensación de catástrofe o de peligro inminente" (Sierra et ál., 2003, p. 8). La angustia se presenta como:

Una emoción compleja, difusa y displacentera, presentando una serie de síntomas físicos que inmovilizan al individuo, limitando su capacidad de reacción y su voluntariedad de actuación; para que ocurra ésta, es necesaria la interacción entre distintos factores de tipo biológico, psicológico y social. (Sierra et ál., 2003, p. 21)

Así podemos observar una diferencia entre ambos conceptos. La ansiedad se caracteriza por la anticipación de algo que no se sabe si sucederá y cuyo síntoma parte de un conflicto interno que predispone a quien lo padece a la inminente sensación de peligro; mientras tanto, la angustia posee un estado o sentimiento de inmovilización, sumado con matices biológicos, sociales y existenciales. Pero aun así, podemos ver cómo una participa de la otra, teniendo en común algo que queda fuera del control del individuo, y que puede llevar a este a estados psicóticos más graves.

Ansiedad y angustia, como situaciones desagradables del personaje, implican una pérdida de control, de estabilidad emocional. El personaje femenino 
se ve envuelto en estas circunstancias que atrofian su vida cotidiana y pasa de una supuesta "estabilidad" a un decaimiento y desmoronamiento, extraviándose en el laberinto que la conducirá al horror.

El personaje principal de Dávila (2014) nos confiesa su estado emocional y anímico desde el inicio de su historia: "Llevábamos entonces cerca de tres años de matrimonio, teníamos dos niños y yo no era feliz. Representaba para mi marido algo así como un mueble" (p. 19). La infelicidad y la soledad de la mujer son predisposiciones que logran desencadenar un sentimiento de sofocación, de tristeza, lo cual encamina al personaje a estar expuesto a una ansiedad crónica. Dichas situaciones somáticas se añaden al cuadro sintomático de la mujer. Sierra, Ortega y Zubeidat puntualizan: “[...] ansiedad es un estado emocional que puede darse solo o sobreañadido a los estados depresivos y a los síntomas psicosomáticos cuando el sujeto fracasa en su adaptación al medio" (Sierra et ál., 2003, p. 12). Aparte, la actitud de desagrado y derrumbamiento manifiesto en la protagonista se convierten en el diario vivir y dan paso al choque, a la marginación de su contexto y, por ende, al desmoronamiento de su propia tranquilidad:

Los personajes de Amparo Dávila son seres como nosotros que se crean a través de estas constantes, a veces no de una soledad física, pero sí de una soledad interna, de incomprensión y vacío. De un miedo dentro del fracaso, a algo, a lo no presente pero que acecha su cotidianidad y logra reacciones de angustia y paranoia. (Bravo, 2008, p. 13)

Lo anterior juega un papel preponderante en cuanto la propagación del sentimiento pulsional de la protagonista. Las derrotas moral y psicológica aparecen como consecuencias de la nula integración del personaje: "Vivíamos en pueblo pequeño, incomunicado y distante de la ciudad. Un pueblo casi muerto o a punto de desaparecer" (Dávila, 2014, p. 19). Aquí, el ahogo y la sofocación afloran, la mujer se convierte en campo fértil para que su personalidad y su moral dañada se sumerjan en los planos de ansiedad. Ella no puede desde un inicio integrarse a su entorno ni a su vida nueva. Se abandona y desespera. Aunado con ello, el estado de desolación acaba con su fortaleza; así, la protagonista fracasa en su adaptación como individuo, en completo desamparo.

El desequilibrio donde se enclava la mujer mantiene al borde su 
estabilidad emocional; la ansiedad encuentra nido y cobijo en el interior del personaje femenino. Su encuentro con la indeterminación, con lo que no puede concretar, origina un abismo de desesperación y, allí, se abandona a sí misma. Dice la protagonista:

Mi vida desdichada se convirtió en un infierno. Supliqué a mi marido que no me condenara a la tortura de su compañía. No hubo manera de convencerlo a que se lo llevara. [...] Perdí la poca paz de que gozaba en la casona. (Dávila, 2014, p.19)

Su ansiedad es real y “[...] aparece ante la relación que se establece entre el yo y el mundo exterior; se manifiesta como una advertencia para el individuo, es decir, le avisa de un peligro real que hay en el ambiente que lo rodea" (Sierra et ál., 2003, p. 23), pero el marido hace caso omiso ante su estado de alerta. El ama de casa cumple cabalmente con cada uno de los síntomas enunciados. $\mathrm{Su}$ estado de ansiedad se incrementa: agitación, aislamiento y miedo comienzan a anidar dentro de su cuerpo; la sintomatología necesita concretarse en algo físico. De esta manera, al enfrentarse con el huésped, el grito de la protagonista se libera, ha dirigido todos sus padecimientos a la figura del nuevo inquilino. El huésped se convierte en un portador de lo que, por tanto, tiempo se gestó en la mujer y la precipita al horror.

\section{Angustia y agorafobia}

El confinamiento guarda ciertos claros de alivio al personaje femenino, como puede notarse en el cuidado que le procura a su jardín. No obstante, esta es solo otra de las características que alguien agobiado posee en su red de tribulaciones. Según Arenas y Puigcerver (2009):

La agorafobia es una de las consecuencias más discapacitantes (sic) del trastorno de angustia. Consiste en tener miedo a presentar ataques de pánico, lo que lleva a los sujetos a confinarse en el hogar, un espacio donde pueden controlar las actividades y los estímulos. (p. 2)

El personaje femenino nos da muestras de su día a día. El encierro que procura la mantiene contenida y apacible, pero disfraza un síntoma:

Pero yo amaba mi jardín. Los corredores estaban cubiertos por enredaderas que floreaban casi todo el año. Recuerdo cuánto me 
gustaba, por las tardes, sentarme en uno de aquellos corredores a coser la ropa de los niños, entre el perfume de las madreselvas y las buganvilias. (Dávila, 2014, p. 20)

No obstante, aunque su andar cotidiano en el jardín le proporciona cierto sosiego, sigue recluida en el interior de su hogar. La aversión que siente por el pueblo donde vive la hace refugiarse en un lugar donde ella puede tener el dominio de la situación, donde le es posible controlar incluso los estímulos; sin embargo, todo ello colapsa con la presencia del huésped: "Lo sentía atrás de mí... yo arrojaba al suelo lo que tenía en las manos y salía de la cocina corriendo y gritando como una loca. Él volvía nuevamente a su cuarto como si nada hubiera pasado" (Dávila, 2004, p. 20). El enclaustramiento autoinfligido la sentencia a vivir con su voluntad en manos del extraño; los límites y su cordura se regalan al libre tránsito del actuar de otra entidad.

La mujer vive recluida, sus andanzas según la narración van entre el jardín y los cuartos de la casona. Su perímetro es estrecho, el ahogamiento que le provoca su falta de contacto social la deja a merced de los adversarios. La relación fallida y decadente del matrimonio es un factor importante que recae en infelicidad y desmotivación, por lo cual pierde fuerza y carácter:

La pérdida o la afección de algunas relaciones interpersonales importantes [marido] se relacionan con el inicio o la exacerbación de un trastorno de angustia. Una de las consecuencias frecuentes de este trastorno es la presencia de desmoralización, que lleva a muchos individuos a sentirse desmotivados, avergonzados e infelices por las dificultades que experimentan al llevar a cabo sus actividades diarias. (APA, 2003, p. 484)

Aparte del menosprecio por parte del marido hacia ella, tiene que enfrentar la abominación diaria del nuevo inquilino. El cuadro de angustia se torna entonces crónico. La vorágine cobra fuerza. Ambos antagonistas la emboscan por dos frentes: por un lado se encuentra la figura grotesca del huésped, por otro encontramos el miedo que le produce el marido. Los antagonistas someten tanto en presencia como en lejanía la cordura del ama de casa: 
Como la puerta de mi cuarto queda siempre abierta, no me atrevía a acostarme, temiendo que en cualquier momento pudiera entrar y atacarnos. Y no era posible cerrarla; mi marido llegaba siempre tarde y al no encontrarla abierta habría pensado... Y llegaba bien tarde. Que tenía mucho trabajo, dijo alguna vez. Pienso que otras cosas también lo entretenían... (Dávila, 2014, p. 21)

El personaje femenino entra en crisis: el estar en su morada resquebraja su perspectiva. Su angustia, su abandono y su latente sentimiento de amenaza y peligro, la dejan expuesta. Alfried Längle añade: “La amenaza física o psíquica pone al ser humano, como ser personal-existencial, frente a su posible destrucción o la pérdida de sostén o de estructuras ordenadas que le dan el suelo para el despliegue de su poder-ser" (Längle, 2005, p. 1). Este peligro de perder su mundo y su integridad sostienen el fundamento de su horror: "Yo no salía más. ¡Allí está ya, Guadalupe!" (Dávila, 2014, p. 20). La mujer ha estado en un ambiente de constante amenaza, vive en una situación movediza y agobiante a causa de los antagonistas. No posee suelo firme, se ahoga en sus tribulaciones.

\section{Horror}

El horror se presentará como lo menciona Lovecraft (2014):

El verdadero cuento de horror es algo más que un asesinato encubierto, criaturas grotescas o una imitación de otras historias de terror establecidas de acuerdo con el canon. Una cierta atmósfera de fuerzas desconocidas, opresivas e inexplicables deben estar presentes; y debe haber una pista, expresada con una seriedad y un portento tales, que se conviertan en su temática, esa gran y terrible concepción del pensamiento humano: una maligna y singular supresión o derrota de esas leyes fijas de la naturaleza, las cuales son nuestra única seguridad en contra de los asaltos del caos y los demonios del espacio insondable. (párr. 6. Traducción propia) ${ }^{1}$

En estrecha relación con lo anterior, David Roas menciona otra particularidad que da mayor soporte a los elementos desconocidos e inexplicables que establece Lovecraft: “[...] los motivos que componen el universo fantástico son expresiones de una voluntad subversiva que, ante todo, busca transgredir esa razón homogeneizadora que organiza nuestra percepción del mundo y de nosotros mismos" (Roas, 2011, p. 14). De esta forma, distintos elementos propios del 
universo fantástico son parte constitutiva y fundamental en la construcción del horror en el relato.

Se analizarán tres situaciones mencionadas por Howard Phillips Lovecraft (2014, párr. 2) para la escritura del cuento de horror y cómo estas se reflejan en el relato daviliano:

1) "Una cierta atmósfera de fuerzas desconocidas, opresivas e inexplicables deben estar presentes". Esta primera característica se pone de manifiesto recién comienza el cuento. La protagonista comienza a colapsar desde que observa a su enemigo, quien será su opresor durante la trama de la obra. El hecho de que una criatura como el huésped se haga presente en su hogar, colisiona con la poca estabilidad de la mujer. Para ella es incomprensible la aparición del extraño ser y el influjo macabro que él mismo le ocasiona. También se añade el actuar de su marido y el doble abuso al que se ve sometida: primero, el avasallamiento padecido por el régimen machista en el que se encuentra, se siente sobrepasada y tiene miedo de su propio cónyuge; segundo, que aparece como una burla grotesca, el marido vuelve a salir de viaje encargando a su esposa el cuidado del extraño. La aparición del dúo marido-huésped se torna inexplicable desde el punto de vista de los inquilinos, pero es totalmente justificable para el desarrollo de un cuento de horror.

Los síntomas de ansiedad y angustia de la mujer se vuelven incontrolables por la estadía de su adversario. El control y la cordura se derrumban: se genera el sendero del horror.

2) "Una maligna y singular supresión o derrota de esas leyes fijas de la naturaleza". El personaje siniestro como tal representa esta característica; sus descripciones nos llevan a imaginar como lectores un ser que desafía el reino animal:

Grandes ojos amarillentos, casi redondos y sin parpadeo [...]; dormía hasta el oscurecer [...]; ser tenebroso [...], su alimentación se reducía a carne, no probaba nada más [...]; golpeando cruelmente al niño [...]; vivió muchos días sin aire, sin luz, sin alimento... Al principio golpeaba la puerta, tirándose contra ella, gritaba desesperado, arañaba [...]; creo que vivió cerca de dos semanas. (Dávila, 2014, pp. 19-23) 
El relato nos absorbe en su atmósfera tenebrosa. La estadía del huésped y sus usos no van acorde a lo establecido por el orden natural. Su concepción, la forma en que se contempla, su totalidad irradia espanto. Esta malignidad se percibe desde que el adversario se adueña del curso de la trama. En la confrontación de la protagonista y su antagonista, este último irrumpe y de manera violenta transgrede la realidad del ama de casa, una realidad agobiante pero contenida.

3) Pérdida de la "única seguridad en contra de los asaltos del caos y los demonios del espacio insondable". La protagonista dice: "La misma noche de su llegada supliqué a mi marido que no me condenara a la tortura de su compañía. No podía resistirlo; me inspiraba desconfianza y horror" (Dávila, 2014, p. 19). La única seguridad que poseía era la de sentir refugio en la casona; esto la termina de sentenciar al infierno, al despojo en tierra baldía. Su poca posesión es saqueada y adueñada por el nuevo inquilino. En caos, no solamente la tomaron por asalto, también sufre de un cambio de rol: ella se ha convertido en el huésped, "Yo no salía más". La criatura tenebrosa ha tomado posesión de la casona, va y viene a placer, le sirven de comida o entretenimiento; la mujer siempre se sintió ajena en el pueblo, sentenciada a una vida de enclaustramiento, no es rival para el nuevo propietario de la casa. Sin protección, su vida y la de quienes la aprecian se precipitan al abismo insondable. Encontramos en Roas una referencia importante que cobija lo anterior:

Porque el relato fantástico sustituye la familiaridad por lo extraño, nos
sitúa inicialmente en un mundo cotidiano, normal (el nuestro), que
inmediatamente es asaltado por un fenómeno imposible - y, como
tal, incomprensible- que subvierte los códigos - las certezas- que
hemos diseñado para percibir y comprender la realidad. En definitiva,
destruye nuestra concepción de lo real y nos instala en la inestabilidad
y, por ello, en la absoluta inquietud. (Roas, 2011, p. 14)

El juego del horror expuesto en el cuento tiene como base la interacción entre la mujer y su lucha existencial, en contra partida con el nuevo inquilino representado por el ser que puede estar ubicado fuera del orden lógico. Esta situación perturba, es la sustancia que acecha y lastima, destroza el equilibrio, se manifiesta en lo físico y en lo psíquico, lo que en conjunto produce el caos. 


\section{El huésped como símbolo}

El antagonista hace sentir su dominio tanto al mostrarse como al ocultarse. Aunque la descripción que nos otorga el ama de casa es aterradora, el huésped logra su plenitud cuando representa algo más que una presencia. Esta plenitud tiene un doble origen: lo concreto y lo abstracto. En lo concreto se encuentra lo material, lo que podemos ver y palpar, lo que se entiende al demostrarse con nuestros sentidos; este aspecto queda enmarcado en la fisonomía del huésped: "Con grandes ojos amarillentos, casi redondos y sin parpadeo, que parecían penetrar a través de las cosas y de las personas" (Dávila, 2014, p. 19), y cuando se da constancia de sus extraños hábitos dentro del hogar:

Se situaba siempre en un pequeño cenador, enfrente de la puerta de mi cuarto. Lo descubría en algún oscuro rincón del corredor, bajo las escaleras. Solamente hacía dos comidas, una cuando se levantaba al anochecer y otra, tal vez, en la madrugada antes de acostarse. Toda su alimentación se reducía a carne, no probaba nada más. (Dávila, 2014, pp. 20-21)

La existencia del ente se concreta gracias a las descripciones y demostraciones tanto de su protagonista como las de su ama de llaves. Dentro de lo abstracto podemos situar el mismo sentimiento de opresión y amenaza que el antagonista confiere a las dos mujeres y sus hijos; aparte, el historial de ansiedad, angustia, abandono que ya hemos revisado anteriormente en este trabajo; lo abstracto complementa y es lo que, hasta cierto punto de la historia, termina por subyugar a los habitantes de la casa. Beuchot (2004) nos menciona lo siguiente acerca del símbolo:

El símbolo es el signo que une dos cosas, dos elementos o dos dimensiones. Así, lo material con lo espiritual, lo empírico con lo conceptual, lo literal con lo metafórico o alegórico o figurado. Tiene dos partes. Tenemos la parte individual o concreta del símbolo, y ella nos lleva a la universal y abstracta; la sensorial nos lleva a la conceptual; la corporal a la espiritual. Al juntarse las dos partes, hay un límite en el que se unen, se conectan. (p. 144)

El antagonista une precisamente estas disposiciones mencionadas por Beuchot. Su presencia física materializa el trasfondo sintomático de la protagonista. Ansia, angustia y horror, se concentran en su persona; él es el estado corpóreo del tormento que ha vivido el ama de casa. 
La mujer proyecta sus estados crónicos de ansiedad y angustia ante la figura de su adversario. El huésped representa el sufrimiento y el padecer de la mujer, así también es la "supresión de las leyes naturales" que menciona Lovecraft. Por ello, el antagonista es un símbolo: "Conecta lo emocional y lo conceptual, lo inconsciente y lo consciente, lo sensorial y lo espiritual" (Beuchot, 2004, p. 145). Tenemos entonces que el antagonista guarda un doble significado: el referente, lo que a simple vista nos denota su presencia como lo que se impone, lo repulsivo, la invasión; pero también nos evoca lo incomprensible, el escalofrío, lo oculto, la acumulación del sufrimiento de la mujer: el huésped es un símbolo del estado psicosomático del personaje femenino el cual acentúa el desorden de su realidad vivencial. Mauricio Beuchot menciona que el símbolo nos hace acceder a: “Algo concreto que nos lleva a algo abstracto, algo empírico que nos lleva a algo trascendental, algo físico que nos lleva a algo metafísico, o, finalmente, algo natural que nos lleva a algo sobrenatural" (2007, pp. 15-16). La reacción de la mujer conjuga estos aspectos mencionados. Su sintomatología y el padecer constante han reaccionado ante el antagonista. Estos sentimientos y emociones que no podía concretar, ahora los materializa y el vehículo es su adversario: el ente que aparece frente a ella posee esta ambigüedad del símbolo. El antagonista representa lo que se ha gestado durante tanto tiempo en la psique de la mujer.

El estado anímico del personaje principal es precario; decae y se abate con cada manifestación de su contexto, ya sea de índole propia (su vida, su percepción, la casa) o ajena (marido, pueblo, lo venidero). Esta mortificación desestabiliza al protagonista, es un tormento que no puede materializar pero que la combate día a día. El huésped por ello es el símbolo: lo presente, lo que puede ver; y lo oculto, el desorden de la naturaleza humana.

Ansiedad, angustia y horror hacen de ella una figura vulnerable, totalmente expuesta a la opresión y sumisión, un blanco fácil para las figuras absolutistas que aparecen dentro del cuento: el huésped y el marido. Está incapacita para lograr actos voluntarios, se confina en su cuarto, su perímetro se vuelve más cerrado; la escasa movilidad en su hábitat se redujo y cedió terreno a lo extraño; su asfixia se 
confunde con lo avasallador de sus antagonistas. El trastorno que aflora en ella la coloca en un grado de deterioro moral, psicológico; indefensa, no actúa, se rinde ante la estadía del huésped: "No fui la única en sufrir con su presencia. Todos los de la casa — mis niños, la mujer que me ayudaba en los quehaceres, su hijitosentíamos pavor de él" (Dávila, 2014, p. 19).

\section{Del lector del cuento fantástico}

En el relato fantástico, el autor deja que sea el lector quien interprete y construya los desconcertantes acontecimientos de la historia narrada. Para ello el lector deberá tener en cuenta también el valor de lo silenciado, de lo implícito o de lo meramente sugerido: "El relato fantástico pone al lector frente a lo sobrenatural, pero no como evasión, sino, muy al contrario, para interrogarlo y hacerle perder la seguridad frente al mundo real" (Roas, 2001, p. 8).

Lovecraft (2016) menciona: "El primer énfasis debe darse en sugerencias tenues, pistas que sean imperceptibles e insinuaciones de detalles asociados que expresen vagos estados de ánimo y construir una vaga ilusión de extraña realidad de lo irreal” (p. 4. Traducción propia)². La figura del extraño huésped nos otorga este énfasis: su presencia inexplicable como invitado, los pasos imperceptibles, la fuerza que emana del ente; son algunos de los guiños y sugerencias dispuestos en la trama por parte del autor, que hacen que el lector refigure como situaciones desagradables tanto para la protagonista como para él como recreador de la trama. Se reafirma la particularidad fantástica de la lectura $\mathrm{y}$ de quien lee.

Aquí es donde el lector debe ser partícipe, uno que pueda lograr inmiscuirse no solamente en la trama de la narración, sino que debe ser a la vez un creador del ambiente: “[...] lo fantástico conlleva siempre una proyección hacia el mundo del lector, pues exige una cooperación y, al mismo tiempo, un envolvimiento del lector en el universo narrativo" (Roas, 2009, p. 105). De esta manera, al recrear dichos espacios, termina de componer las sutilezas, sentir lo "incomprensible", los estados de ánimo, la agitación y por fin enredarse con la ansiedad, la angustia y el horror de la protagonista, desde su propia refiguración lectora. 
Es necesario que el lector participativo posea esta competencia de acompañamiento de la lectura, la cual le ayuda a crear una atmósfera de misterio. Esta competencia participativa y creadora hace que el lector elabore poiesis para complementar la narración al inmiscuirse en la creación de la "extraña realidad de lo irreal", lugar donde existe lo fantástico. Mediante tal acción se logra el horror dentro del cuento. Lo anterior es la fundamentación del aspecto fantástico: el lector concreta su participación al ir fraguando y modelando las características dispuestas dentro de la trama. A través de lo indecible, se solidifican lo emocional, lo inesperado, lo que no podemos ver dentro del cuento, pero que lo sentimos por medio de nuestra propia creación de lo imaginario. El lector que se inmiscuye dentro del cuento de horror debe " $[\ldots]$ asumir la indeterminación, que es una porción de significado que se nos queda siempre un poco más allá y que no puede ser aprehendida debido a la limitación interpretativa del intelecto humano" (Ramírez-Arballo, 2010, p. 17). En este tenor expuesto, añadimos que dentro de dicha limitación, este desconocimiento del significado, el sentimiento de horror es donde anida y aflora nuestra capacidad de espanto ante el simple hecho de lo desconocido.

\section{Conclusiones}

La ansiedad y la angustia crónicas se transforman en horror; en el sentimiento que no se puede controlar y cuyas reacciones son también incontrolables. En el momento en que el huésped se descubre como ser material y vulnerable, es decir, cuando es objeto del furioso enviste de la protagonista, la mujer retoma el control de sus decisiones, de su vida: "Guadalupe y yo pasamos casi toda la noche haciendo planes” (Dávila, 2014, p. 22). Con la última acción realizada por las mujeres, el horror pasa a formar parte de lo ordinario, da medio giro y se presenta como venganza de la mano de Guadalupe y su patrona.

Al tener el control de sus decisiones, cuando ellas pueden canalizar y dar significado a su existir, es cuando aniquilan el horror: lo innombrable se define, el odio como liberación, como un volver en sí. La muerte del huésped pone en orden su estadía dentro de su hogar. La protagonista se supera y puede trascender su horror. Al final, con frialdad, da la noticia a su marido, sin titubeos o miedo, con entera certeza. 


\section{Notas}

1 The true weird tale has something more than secret murder, bloody bones, or a sheeted form clanking chains according to rule. A certain atmosphere of breathless and unexplainable dread of outer, unknown forces must be present; and there must be a hint, expressed with a seriousness and portentousness becoming its subject, of that most terrible conception of the human brain - a malign and particular suspension or defeat of those fixed laws of Nature which are our only safeguard against the assaults of chaos and the dæmons of unplumbed space.

2 Prime emphasis should be given to subtle suggestion imperceptible hints and touches of selective associative detail which express shadings of moods and build up a vague illusion of strange reality of the unreal.

\section{Referencias bibliográficas}

Arenas, C. \& Puigcerver, A. (2009). Diferencias entre hombres y mujeres en los trastornos de ansiedad: una aproximación psicobiológica. Escritos de Psicología, 3(1), 20-29. Recuperado de http://scielo.isciii.es/scielo. php?pid=S1989-38092009000300003\&script=sci_arttext.

Beuchot, M. (2004). El ser del símbolo. En M. Beuchot, Hermenéutica analógica y símbolo (pp. 144-147). Ciudad de México: Herder.

Beuchot, M. (2007). Símbolo, analogía e iconicidad. En M. Beuchot, Hermenéutica analógica, símbolo, mito y filosofía (pp. 13-24). Ciudad de México: Universidad Nacional Autónoma de México.

Bravo Alatriste, P. K. (2008). Amparo Dávila y las cuentistas del género fantástico en el medio siglo. Tema y variaciones de literatura: la generación de medio siglo I. Las escritoras. 30, 133-155. Recuperado de http://zaloamati.azc.uam.mx/bitstream/handle/11191/2696/Amparo_ Davila_y_las_cuentistas.pdf? sequence $=1 \&$ isAllowed $=\mathrm{y}$.

Dávila, A. (2014). El huésped. En A. Dávila, Cuentos reunidos (pp. 19-23). Ciudad de México: Fondo de Cultura Económica.

American Psychiatric Association - APA. (2003). Trastornos de ansiedad. En Manual diagnóstico y estadístico de los trastornos mentales DSM-IV-TR (pp. 477-544). Barcelona: MASSON S. A. 
Längle, A. (2005). La Búsqueda de Sostén. Análisis Existencial de la Angustia. Terapia Psicológica, 23(2), 57-64. Recuperado de http://www.redalyc. org/pdf/785/78523206.pdf.

Lovecraft, H. P. (2014). Supernatural horror in literature. Australia: The University of Adelaide. Recuperado de http://ebooks.adelaide.edu.au/1/ lovecraft/hp/supernatural/index.html.

Lovecraft, H. P. (2016). "Notes on writing weird fiction". En The Collected Works of H.P. Lovecraft. Recuperado de https://archive.org/stream/ TheCollectedWorksOfH.p.Lovecraft/The-Collected-Works-of-HPLovecraft\#page/n11/mode/2up.

Ramírez-Arballo, A. (2010). El lector analógico. Revista Hermes Analógica, 1. Recuperado de https://bit.ly/2MFgCyc

Roas, D. (2001). "La amenaza de lo fantástico". En D. Roas, Teorias delofantástico (pp. 7-44). Madrid: Arco Libros.

Roas, D. (2009). "Lo fantástico como desestabilización de lo real: elementos para una definición". En T. López Pellisa \& F. Moreno Serrano (Eds.), Primer Congreso Internacional de literatura fantástica y ciencia ficción (pp. 94-120). Madrid: Asociación Cultural Xatafi. Recuperado en https:// teorialiteraria2009.files.wordpress.com/2016/05/roas-lo-fantasticocomo-desestabilizacic3b3n-de-lo-real.pdf

Roas, D. (2011). Tras los límites de lo real: Una definición de lo fantástico. Madrid, España: Páginas de Espuma.

Sierra, J. C., Ortega V., \& Zubeidat, I. (2003). Ansiedad, angustia y estrés: tres conceptos a diferenciar. Revista Mal Estar e Subjetividade, 3(1), 10-59. Recuperado de http://pepsic.bvsalud.org/pdf/malestar/v3n1/02.pdf 